\title{
Message from the President
}

\section{Dear Colleagues;}

On behalf of The Japanese Association of Special Education (JASE), I am very pleased to inform you of our official message to academic worlds related to special education. JASE was founded in 1962, and more than 4,000 researchers and professionals are involved as active members in 2013. JASE is the association focusing on academic research in Japan, and aims to search for the improvement of education, welfare and living for people with disabilities. The research done by the members of JASE cover from fundamental questions to practical and/or applied ones, and JASE deals with populations that include persons with all kinds of disabilities, as well as youthful delinquents. This comprehensiveness is one of the salient features of the Association. JASE has been publishing the official Journal, Japanese Journal of Special Education (JJSE), bimonthly written in Japanese. Since 2000, one of the six issues of JJSE has been published in English in every year.

To expand our academic facilities, we have just started new official Journal, Japanese Special Education Research (JSER), entirely written in English in February 2013. This new Journal covers every field and topic related to special education. And from now on, JSER will be published in February and August every year. JSER accepts from all over the world manuscripts from researchers and professionals who are engaged in the fields of education, welfare and living for people with disabilities. Submitted manuscripts will be processed according to our editorial guideline. You will find many more details in "Information for Contributors" in this issue.

We are looking forward to receiving your contributions in the near future.

Sincerely yours,

Hisaki Ozaki

New President, The Japanese Association of Special Education

Professor, Ph.D., Ibaraki University 